\title{
Moral Basics of Teaching: Vital Issues and Pitfalls
}

\author{
Natalia Maklakova ${ }^{1, *}$, Evgeniy A. T. Kharitonov ${ }^{1}$, Elena Besedina ${ }^{2}$, Ivan Maklakov ${ }^{3}$ \\ ${ }^{1}$ Kazan Federal University, Russia \\ ${ }^{2}$ Saint Petersburg Electrotechnical University "LETI", Russia \\ ${ }^{3}$ Kazan Cooperative Institute, Russia
}

Received July 12, 2019; Revised September 20, 2019; Accepted September 27, 2019

Copyright $(2019$ by authors, all rights reserved. Authors agree that this article remains permanently open access under the terms of the Creative Commons Attribution License 4.0 International License

\begin{abstract}
This study presents the results of a research into ethical foundations as a backbone element of teaching process. In order to obtain a more complete picture in this regard, this work follows three main directions. Firstly, basic documents regulating legal aspects of the issue are examined to find out if the modern Russian school is provided with relevant regulations; secondly, a survey is conducted along with subsequent clarifying interviews of 55 secondary school teachers of Kazan as well as 65 senior students of pedagogical departments of Kazan Federal University. The findings show a gap between growing demands for teachers' ethical qualities and behaviors on the one hand, and existing schooling practices on the other hand. Furthermore, the research analyzes the nature and the reasons of the gap and suggests ways to overcome this discrepancy.
\end{abstract}

Keywords Student, Learning, Teacher, Education, School, Pedagogical Ethics, Moral Values

\section{Introduction}

Problems associated with pedagogical ethics have been the focus of study in pedagogy since ancient times, whose foundations were laid by Aristotle, Plato, and Socrates, and then developed in the works of Spinoza, Hegel, Kant, Rousseau, Pestalozzi, Tolstoy, Ushinsky, and other scholars and teachers. Today, however, ethical aspects of education are particularly vital in the context of changes taking place in modern societies. Therefore; erosion of moral values, priority of material aspects of life over spiritual ones, as well as loss of clear ideas about good and evil are all considered as characteristics of modern life. Moreover, people are overwhelmed by uncontrolled flow of information, which possibly carries serious risks for society, since it is associated with promotion of violence, terrorism, illicit drugs, and pornography; threatening the existence of society as a community of civilized individuals. Easy availability of information of any kind is also increasingly becoming an objective factor and an inevitable component of educational process for younger generations. Modern "digital" society has further exacerbated the existing problems and added new ones, such as dilemmas of freedom and meaning, technophilia and technophobia, the universal and the local, good versus evil information, freedom and responsibility of media representatives, etc. The nature of these contradictions indicates the spiritual and moral crisis of the modern man as well as the crisis of the meaning of their existence, which cannot but affect education systems, revealing the problems of societies like litmus papers. Therefore, it is not surprising that ethical foundations of life, in general, and moral components of education system, in particular, are currently in the focus of pedagogical theory and practice, given the fact that it is the education system that, one way or another, forms a person who is able or unable to solve moral problems.

The review of the related literature on the problem showed that ethical foundations of learning had been studied in many aspects and from different points of view. Thus, a number of authors had concluded that ethical issues of training could not be solved by simply applying certain ready-made rules. Their solution was always associated with moral choices, which, in turn, were closely related to the problems of personal development and social justice (Campbell, 2008; Higgins, 2010; Newman, 2012). In addition, the moral choices implied children's rights to an open future and ability to overcome contradictions between the interests of individuals and those of societies (Newman, 2012). However, the researchers noted that the modern education system aimed, in the first place, at training, ignoring the development of individuals' personality as well as the formation of their moral foundations (e.g., Holma, 2012; Kurmanali et al, 2018). Moreover, there was lack of adequate tools to assess ethical maturity in students, although attempts had been made to analyze ethical behaviors of modern learners (Newman, 2012), where it was noted, in particular, that it was characterized by a 
tendency to cheating, which, according to the authors, suggested a low level of their moral development. A special place in the research had been also given to the question of what should be the ethical behavior of teachers, as the central figures of an educational process. First, thinking about the role of teachers, scholars had noted that it was not a good idea to reduce their roles to a set of certain actions whose quality could be assessed by that of the resulting "product" (Sockett, 1993; Sanger, 2012). This was a certain mission and a vocation whose nature was aimed at solving various moral problems (Veugelers, 2011). The solution of these problems, according to the researchers, could be based on different approaches, divided into three large groups: deontological, performance, and morally-oriented.

Thus, the representatives of the first approach believe that teachers need to be guided by the concepts of their rights and duties and those of other people in their decisions and actions. In other words, teachers' behaviors can be considered moral if they fulfill their responsibilities (i.e. explicit and implicit) towards individuals or social institutions (e.g. schools). The second approach assesses teachers' actions in terms of their consequences or results. An action can be thus regarded moral if it can bring good to all. This implies either good pleasure, or happiness, or personal preferences and desires. In contrast to the first two approaches, seeking to determine what the moral action should be, the third theory analyzes teachers' moral personality. Thus; Sockett identified five qualities underlying teachers' morality including (a) "intellectual honesty" as the ability to perceive true knowledge, to distinguish between fact and fiction, and to form faith in students; (b) "courage" implying willingness to defend ones' principles, even if it can lead to negative consequences; (c) "attentive and interested attitudes to others" (people, ideas, and objects), which involves empathic understanding, sensitivity, and responsiveness; (d) "justice" representing respectful attitudes to students like equal thinking subjects with their own interests and needs contributing to their moral growth; and (e) "life wisdom" that requires reflection and can allow teachers to behave in a balanced and reasonable way i.e. to understand what to do, when, and why (Sockett, 1993). Researchers had also considered the characteristics of moral actions and qualities of teachers' personality. However, insufficient attention had been paid to how to translate such characteristics and qualities into a practical set of rules that could determine teachers' behaviors. Distinguishing three main deontological principles, this problem had been also discussed by Sanger (Sanger, 2012). Firstly, students have the right to a properly organized learning process wherein teachers' decisions are not made arbitrarily, unsystematically, or subjectively. This provides fair and safe environments for learners along with correct distribution of rewards and penalties. Secondly, teachers have the right to have autonomy (or intellectual freedom) and to develop autonomy in learners, which implies respect for independent opinions and an opportunity to learn about different approaches to a problem. Thirdly, teachers are supposed to treat all students equally, without any exceptions. Other researchers had further focused on some other rules (no harm to students, fair assessment by tests, etc.). Ultimately, lack of a coherent set of norms for teachers' ethical behaviors had brought about confusion in assessing various practical situations.

Thus, the moral aspect of teaching is becoming its backbone component, laying a basis for individuals' development and making them able to confront "immoral" challenges of modern digital society. The central figure, the subject and the means of education, as well as the guarantor of compliance with moral standards should be the teacher who possesses a certain set of qualities. However, the question of how fully these requirements are today implemented in modern schools becomes relevant. The aim of this research was to address this question.

\section{Literature Review}

Every organization has a code of ethics tailored to its professional structure, called professional ethics. Education is also recognized as a professional system. Accordingly, practitioners as individuals responsible for educating students should be aware of and adhere to the principles of teachers' professional ethics that can guarantee the health of the teaching-learning process at schools and increase teachers' commitment to respond to students' needs (Bryman, 2004; Jenaabadi, 2013).

According to the principles of teachers' professional ethics, a teacher must adhere to ethical principles in two dimensions; first, in order to have an impact on learners' behaviors and thoughts, that is, they must adhere to ethical virtues and know the most effective ways to do so. Transferring positive moral values is revealing them in teachers' real behaviors. Second, in order to fulfill students' educational needs, they must best perform their educational responsibilities with due regard to the highest ethics of their professional duties (Sanger, 2012; Velazco \& Padrón, 2019).

Since teachers are in charge of teaching and training, they must also be proficient in the teaching profession and familiar with its ethics, as education is the primary function and mission of schools. Teaching provided by an educational system may also lead to specific behaviors in society that may be ethically questionable. For example, teaching can provide or fail to provide students with the best learning appropriate to scientific developments and community demands; moreover, educational resources, content, and course headings may be designed to reinforce or weaken a particular type of thinking. While there are numerous benefits or disadvantages to the community, the type of teachers' behaviors can have a positive or negative 
impact on students' behaviors (Veugelers, 2011).

\section{Methods}

In order to obtain a more complete picture, the work was organized into three main directions. Firstly, basic documents regulating legal aspect of the issue were studied to find out if the modern Russian school is provided with relevant regulations. Accordingly; the following documents were analyzed: the Constitution of the Russian Federation, the Family Code, the Civil Code, the Civil Procedure Code, the Code of Administrative Offences, the Criminal Code of the Russian Federation, the Federal law "on basic guarantees of the rights of the child in the Russian Federation", the Federal law "on state support of youth and children's public associations", the Federal law "on education", etc. The study was based on the documentary research method that involved the analysis of documents not originally intended for scientific research meeting the following characteristics: authenticity, reliability, representativeness, and accessibility for understanding (Bryman, 2004). The documents used in this analysis met these criteria.

Secondly, a survey was conducted along with the subsequent clarifying interviews of 55 secondary school teachers of Kazan and 65 senior students of pedagogical departments of Kazan Federal University in order to find out:

a) To what extent practical teachers and future teachers were familiar with provisions of these documents and theoretical studies on the problem. Accordingly, the following questions were asked:

1. What basic documents regulating legal aspect of moral components of learning process do you know?

2. What basic provisions of these documents can you list?

3. What problems related to ethical aspects of teaching do you consider the most relevant today?

4. What theoretical works on this problem have you read?

5. What main provisions of these works can you list?

6. What sources did you use to study this problem?

7. What provisions of pedagogical ethics do you consider necessary to follow in pedagogical practices?

b) Which of them the respondents are guided by or plan to use in their practices, why and how they should be used. So, the following questions were raised:

1. What are moral foundations of learning and their role today?

2. How much do you think this problem is relevant to schools today?
3. What categories and notions are included in this concept?

4. What main contradictions associated with this problem can you see in modern schools?

5. What possible solutions can you suggest?

6. Which ones do you use/intend to practice?

7. What moral qualities should a teacher possess?

8. What difficulties do you face / may face in practicing them?

9. What is a teacher's ethical behavior?

10. Do you consider your behavior ethical enough? Why / why not?

11. What are basic characteristics of personality-oriented pedagogy?

Thirdly, a survey was conducted along with the subsequent clarifying interviews of 65 Kazan secondary school children in order to look at school practices from learners' points of view. To this end, the following questions were asked:

1. How can you generally describe atmosphere of your school?
A. Authoritarian
B. Democratic
C. I find it difficult to answer

2. Have you or your friends ever been subjected to any form of violence at school? What kind?
A. Physical abuse
B. Verbal abuse
C. Blackmail
D. Other types (what)

3. What benefits of your school can you name?

4. What negative features do you associate with your school?

5. What qualities do you think a modern teacher should have?

6. What are the main qualities of your favorite teachers?

\section{Results \& Discussion}

The analysis of the relevant documents showed that; first of all, they had been developed in accordance with the basic provisions laid down in the Council of Europe Convention on the protection of human rights and fundamental freedoms; the UN Declaration on the Rights of the Child; the UN Millennium Declaration and Implementation Plan of the UN Millennium Declaration; the UN Action Plan "World Fit for Children", etc. They were also based on the provisions ensuring the rights of the child to survival, development, protection, and active participation in public life, which presupposed the right of the child to preserving their identities (including nationality, name, and family ties), to freedom of expression on issues affecting their lives, to receiving necessary information, to education on the basis of equal 
opportunities, to developing their talents, as well as mental and physical abilities, to respect for their human dignity, etc.

Hence, it was concluded that the ethical basics of education in Russia had a sound legal foundation. However, closer examination demonstrated that the documents regulating the work of school had been aimed at quantity and quality of knowledge and were declarative by nature. The roles and moral qualities of teachers had not been given the due attention, however. Accordingly, it is the teacher who should be not only a source of knowledge, but also a carrier and translator of a certain morality.

It should be noted that the survey of practitioners and future teachers gave rather discouraging results. The majority of the respondents (91\%) could mention only two legal documents on the topic i.e. the Constitution of the Russian Federation and the Law on Education, but were not able to clearly formulate their specific provisions, indicating lack of teachers' awareness of the subject. Only $11 \%$ of the teachers and $4 \%$ of the undergraduates were able to more or less fully articulate the essence of the ethical aspects of education, pointing mainly to the needs for respect among learners and non-use of violence. As well, $100 \%$ of the respondents believed that ethical aspects were relevant for today's school, but the vast majority of them $(87 \%)$ had never really thought about this side of teachers' activities and could not formulate any basic concepts associated with it, as well as the ways of practical implementation of theoretical ideas. Moreover, in individual interviews, $57 \%$ of the teachers admitted that they had often used an authoritarian style of communication with learners and had not seen anything shameful in this fact, considering this style more effective. Additionally, $98 \%$ of the respondents considered their behavior ethical, but could not give its detailed characteristics.

It turned out to be a surprise that $37 \%$ of the teachers in the clarifying interviews had admitted that they were feeling a sense of professional burnout and loss of control when communicating with children. There were several reasons in this respect including overcrowded classes, congested curricula, insufficient qualifications of teachers and their unfitness for difficulties of communicating with learners, fatigue, feeling of helplessness when dealing with children's problems, etc. These teachers had also followed the path of the least resistance and had been guided by their own mood, not children' needs. In the view of authors, such teachers needed support from outside, and special psychological training could thus help most of them.

Therefore, most teachers explicitly or implicitly were practicing an authoritarian style of communication with learners. Recognizing the relevance of the ethical foundations of learning, they were not inclined to ethical behaviors in practice, showing ignorance and unwillingness to develop in this area.

Bearing in mind the results of the teachers' questioning, the findings of the children's survey were not surprising. Despite the fact that almost all the teachers spoke out for humanism and ethical behaviors, $16 \%$ of the learners reported that they had been physically abused at school (hit with a ruler, a pointer, or a book). Moreover, $51 \%$ of the respondents had been verbally abused, $37 \%$ of the schoolchildren had experienced blackmail as a threat of disclosing undesirable information about the child or their family in order to influence their behavior. Additionally, $47 \%$ of the respondents had been subjected to punishment. At the same time, only $39 \%$ of the children noted friendly and respectful attitudes of their teachers, and $27 \%$ admitted that teachers had seen them as second-class people. Among the qualities required for good teachers, the students allocated goodwill $(91 \%)$, justice $(89 \%)$, respectfulness $(89 \%)$, and integrity $(75 \%)$. The same qualities were more or less inherent in the learners' best-loved teachers. In this situation, it was not surprising that the children had developed didaktogenia; i.e. a negative mental state, provoked by the violation of pedagogical tacts on the part of teachers. The term was introduced by Platonov, expressed as a higher neuropsychic tension, fear, and depressed mood with a negative impact on children, making it difficult for them to communicate with people. In the absence of correction of the situation, it could be developed into a neurosis that required special treatment. It should be noted that cases of didaktogenia had been registered only at schools, i.e. in the place where the relationships needed to be based on the principles of humanity and morality. Preventing measures for didaktogenia thus depended on teachers' ethical culture (ethics) (Hudik \& Fesenko, 2015).

The clarifying interviews with the learners also showed that they were extremely sensitive to the personal qualities of teachers and were demonstrating, on the one hand, respect, love, and trust to those teachers who had shown love and respect to them, and, on the other hand, rejection of hypocrisy, injustice, and indifference. Moreover, answering questions about the psychological climate in their school as a whole, they somehow began to talk about their teachers and their qualities, which once again, in author's opinions, confirmed the thesis that the central figure of the education system was the teacher with all the ensuing consequences.

\section{Conclusions}

The present study revealed that the modern Russian school was experiencing a certain moral crisis, which undoubtedly was reflecting the situation in the society as a whole. It should be noted that the Russian society today is going through not only an economic but also a spiritual decline caused by well-known objective reasons, which cannot but affect the development of the educational system. Education has also become a service sector today, 
which has led to a crisis of goals, since the clear idea of what kind of person should be brought up has been lost. A well-developed system of education for a fully developed personality has also reduced to the idea of adaptation to social life. Man is not born with an innate morality, but it is a product of development and education, as the basis of an individual personality. Its role is huge, and therefore it is so important to acquaint a person with moral values as soon as possible. Accordingly, lack of moral education for younger generations is one of the greatest evils of the present time, which must be overcome; otherwise, humanity will reach moral decay.

The ideas of the moral foundations of education and the key roles of teacher in this process have been blurred, leading to a fall in the prestige of teaching profession, as well as to a decrease in the requirements not only for professional but also personal qualities of teachers. As a result, today's school is witnessing many non-professionals who do not know and do not want to know anything about the ethical basics of the pedagogical process. This affects not only children, but also teachers themselves who suffer from professional burnout, disappointment, and depression.

Despite the thorough elaboration of the theoretical foundations of pedagogical ethics, it becomes obvious that pedagogical practice lags far behind the theory. To deal with this contradiction; it is necessary, in authors' opinions, to develop a set of measures involving both strategic (i.e. strengthening educational function of school, increasing prestige of teaching profession, etc.) and tactical aspects (that is, intensifying professional requirements once recruiting teachers, providing systematic education of teachers in this area, monitoring teachers' actions and effective penalties for violations of children's rights, giving moral and material incentives to teachers for professional and personal growth, organizing psychological trainings for teachers, etc.). A special place in this case should be also given to moral education and development of teachers as carriers and translators of moral values. It is suggested, as an example, to introduce a teaching ethics course in the curricula of teachers' training and retraining programs. In addition, development of basic characteristics of cooperative pedagogy in the context of modern provisions of pedagogical ethics can be promising. All these require further complex multidimensional studies.

\section{Acknowledgements}

The work was performed according to the Russian Government Program of Competitive Growth of Kazan Federal University.

\section{REFERENCES}

[1] Braun, V., Clarke, V. (2006). Using thematic analysis in psychology. Qualitative Research in Psychology, 3(20), 77-101

[2] Bryman, A. (2004). Social Research Methods. 2nd ed. Oxford: Oxford University Press

[3] Campbell, E. (2008). The ethics of teaching as a moral profession. Curriculum Inquiry, 38(4), 357-384.

[4] Gross, E. R. (2012). Clashing values: Contemporary views about cheating and plagiarism compared to traditional beliefs and practices. Education, 132(2), 435-440.

[5] Higgins, C. (2010). Introduction: Why we need a virtue ethics in teaching. Journal of Philosophy of Education, 44(2-3), 189-208.

[6] Holma, K. (2012). Fallibilist pluralism and education for shared citizenship. Educational Theory, 62(4), 397-409.

[7] Hudik, V. A., Fesenko Yu, A. (2015). Didaktogenia as errors of upbringing and education of children and adolescents. Bulletin of the University Cherepovetslessnab, 7, 147-151.

[8] Jenaabadi, H., \& Shad, E. M. (2013). Study Of Attitude Of Middle School Students Toward Schools Counselors' Efficacy In Helping Them To Solve Their Study, Job Personal And Family Problems, UCT Journal of Social Sciences and Humanities Research, 1(1): 22-24

[9] Khovanskaya, E. S., Fakhrutdinova, A. V. (2017). Maklakova, N. University as a social phenomenon. Man in India, 97(9), 101- 107.

[10] Kurmanali, A., Suiyerkul, B., Aitmukhametova, K., Turumbetova, Z., \& Smanova, B. (2018). Analysis of the proverbs related to the lexemes" tongue/language". Opción, 34(85-2), 97-115.

[11] Kondrateva Irina, Fakhrutdinova Anastasia, Kapustina Elvina and Vafina Rashida. (2018). UPDATE OF VALUE CENTERED APPROACH FOR SOCIO-STABLE AND SAFE SCHOOL ENVIRONMENT. Abstracts \& Proceedings of INTCESS 2018- 5th International Conference on Education and Social Sciences, 5-7 February - Istanbul, $78-83$.

[12] Mefodeva, M. A., Fakhrutdinova, A. V., Ukhimenko, A. N. (2017). Historical perspectives of spiritual and moral education in India. Man in India, 97(8), 71-77.

[13] Mendoza Velazco, D. J., \& Rivero Padrón, Y. (2019). Teaching Resource for the Teaching of Geometry: Circular Trigonometric Geoplane. International Electronic Journal of Mathematics Education, 14(1), 3-13. https://doi.org/10.12973/iejme/3936 
[14] Newman, O. (2012). No child is an island: Character development and the rights of children. Educational Theory, 62(1), 91-106.

[15] Sanger, M. (2012). The schizophrenia of contemporary education and the moral work of teaching. Curriculum Inquiry, 42(2), 285-307.

[16] Scott, J. (1990). A Matter of Record. Cambridge: Polity Press Cited In Bryman A 2004 Social Research Methods. 2nd Ed. New York: Oxford University Press.

[17] Sockett, H. (1993). The Moral Base for Teacher Professionalism. New York: TeachersCollege Press, 1993.

[18] Sternberg, R. J. (2013). Reform education: Teach wisdom and ethics. Phi Delta Kappan, 94(7), 44-47.

[19] Veugelers, W. (2011). Education and humanism: Linking autonomy and humanity. Springer Science \& Business Media. 